NASA Technical Memorandum 106629

AIAA-94-2079

\title{
Experimental Investigation of Jet-Induced Mixing of a Large Liquid Hydrogen Storage Tank
}

C. S. Lin

Analex Corporation

Brook Park, Ohio

M. M. Hasan and N. T. Van Dresar

Lewis Research Center

Cleveland, Ohio

Prepared for the

6th Joint Thermophysics and Heat Transfer Conference

cosponsored by the American Institute of Aeronautics and Astronautics and the American Society of Mechanical Engineers

Colorado Springs, Colorado, June 20-23, 1994
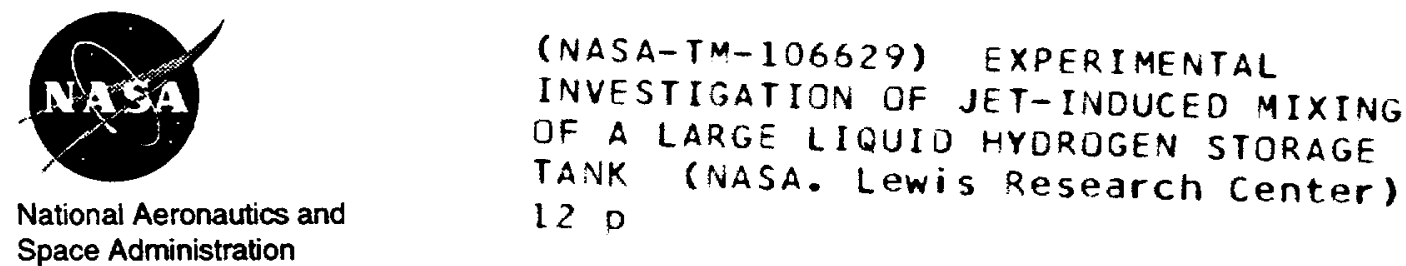

Unclas 


\title{
EXPERIMENTAL INVESTIGATION OF JET-INDUCED MIXING OF A LARGE LIQUID HYDROGEN STORAGE TANK
}

\author{
C.S. Lin \\ Analex Corporation \\ 3001 Aerospace Parkway \\ Brook Park, Ohio 44142 \\ M.M. Hasan and N.T. Van Dresar \\ National Aeronautics and Space Administration \\ Lewis Research Center \\ Cleveland, Ohio 44135
}

\begin{abstract}
$\underline{\text { Abstract }}$
Experiments have been conducted to investigate the effect of fluid mixing on the depressurization of a large liquid hydrogen storage tank. The test tank is approximately ellipsoidal, having a volume of $4.89 \mathrm{~m}^{3}$ and an average wall heat flux of $4.2 \mathrm{~W} / \mathrm{m}^{2}$ due to external heat input. A mixer unit was installed near the bottom of the tank to generate an upward directed axial jet flow normal to the liquid-vapor interface. Mixing tests were initiated after achieving thermally stratified conditions in the tank either by the introduction of hydrogen gas into the tank or by self-pressurization due to ambient heat leak through the tank wall. The subcooled liquid jet directed towards the liquid-vapor interface by the mixer induced vapor condensation and caused a reduction in tank pressure. Tests were conducted at two jet submergence depths for jet Reynolds numbers from 80000 to 495000 and Richardson numbers from 0.014 to 0.52 . Results show that the rate of tank pressure change is controlled by the competing effects of subcooled jet flow and the free convection boundary layer flow due to external tank wall heating. It is shown that existing correlations for mixing time and vapor condensation rate based on small scale tanks may not be applicable to large scale liquid hydrogen systems.
\end{abstract}

\section{Nomenclature}

A liquid-vapor interface area

$\mathrm{C}_{\mathrm{p}} \quad$ specific heat of liquid

$\mathrm{D}, \mathrm{D}_{\mathrm{s}} \quad$ tank diameter, liquid-vapor interface diameter

d jet nozzle diameter

g gravitational acceleration

$\mathrm{Gr}^{*}$ the modified Grashof number, $\mathrm{Gr}^{*}=\mathrm{g} \beta \mathrm{q}_{\mathrm{w}} \mathrm{H}_{l}{ }^{4} / \mathrm{k} v^{2}$

$H_{l}, H_{j} \quad$ liquid height, jet submergence depth

$h_{\mathrm{fg}} \quad$ latent heat of condensation
Ja

$\mathrm{k}$

$m_{c}$

$P, P_{i}, P_{f}$

$\operatorname{Pr}$

$\mathrm{Q}_{\mathrm{bl}}(\mathrm{x})$

$Q_{c}(x)$

$\mathrm{Q}_{\mathrm{bl}}$ *

$\mathrm{Q}_{\mathrm{c}}{ }^{*}$

$Q_{j}$

$q_{w}$

$\mathrm{Ri}$

$\mathrm{Re}_{\mathrm{j}}$

$\mathrm{St}_{\mathrm{c}}$

$T_{b}, T_{j}, T_{s}$

$\mathrm{T}_{\text {dome }}$

$\left(\mathrm{T}_{\mathrm{s}}-\mathrm{T}_{\mathrm{b}}\right)$

$\left(T_{s}-T_{j}\right)$
Jakob number, $J a=C_{p}\left(T_{s}-T_{b}\right) / h_{f g}$

thermal conductivity

average mass condensation rate at the liquid-vapor interface

tank pressure, initial tank pressure, and final tank pressure

Prandtl number of bulk liquid, $v / \alpha$

volume flow rate of the free convection boundary layer along the tank wall

jet volume flow at a distance of $x$ downstream from the jet nozzle

$\mathrm{Q}_{\mathrm{bl}}(\mathrm{x})$ evaluated at $\mathrm{x}=\mathrm{H}_{\mathrm{l}}$

$Q_{c}(x)$ evaluated at $x=H_{j}$

jet volume flow rate at the jet nozzle outlet

wall heat flux

Richardson number evaluated at the begining of each test, $g \beta\left(T_{s}-T_{j}\right)_{i} H_{j} / u_{j}{ }^{2}$

jet Reynolds number, $u_{j} d / v$

average condensation Stanton number, $S t_{c}=m_{c}$ $h_{f g}\left[A_{s} \rho C_{p} v_{s}\left(T_{s}-T_{b}\right)\right]$

bulk liquid temperature, jet temperature, and interace temperature

dome temperature

liquid subcooling

jet subcooling 


$\begin{array}{ll}t_{m,} t_{m}^{*} & \text { mixing time, dimensionless mixing time } \\ u_{j} & \text { jet velocity } \\ v_{1} & \text { liquid volume } \\ v_{s} & \begin{array}{l}\text { average r.m.s turbulent velocity (or turbulence } \\ \text { intensity) at the liquid-vapor interface }\end{array} \\ \mathrm{x} & \begin{array}{l}\text { height (vertical distance) measured from the tank } \\ \text { bottom or downstream distance from } \\ \text { the jet nozzle }\end{array}\end{array}$

Greek Symbols

$\begin{array}{ll}\alpha & \text { thermal diffusivity of liquid } \\ \beta & \text { thermal expansion coefficient of liquid } \\ v & \text { kinematic viscosity of liquid } \\ \rho & \text { liquid density } \\ \sigma & \text { surface tension }\end{array}$

\section{Introduction}

Pressure control of a cryogenic storage tank in low gravity is one of the key advanced technologies being developed in the cryogenic fluid management program at NASA. In pressure control technology, fluid mixing such as axial jetinduced mixing is considered an efficient method to reduce the pressure of a cryogenic tank. In normal gravity, when a partially filled cryogenic tank is subjected to external heating and the fluid is thermally stratified, the tank pressure increases with a rate usually higher than its homogeneous pressure rise rate $^{1}$. Due to the temperature stratification the bulk liquid is generally subcooled. By using a mixer located near the bottom of the tank, the tank liquid is circulated and the subcooled axial jet can be directed towards the liquid-vapor interface. The subcooled jet spreads from the jet nozzle outlet, but remains confined to the axial region. The jet impinges on the liquidvapor interface, which is kept horizontal by gravity, turns radially outward, and eventually deflects down into the bulk liquid near the tank wall and mixes with the bulk liquid. This mixing of the tank liquid by the jet destroys the liquid temperature stratification and induces vapor condensation at the interface, resulting in the reduction of tank pressure. The required mixing time and vapor condensation rate at the interface are the two key elements in the mixing process to reduce tank pressure. The high jet flow rate fluid mixing and the associated vapor condensation results, which are not influenced by the buoyancy effects, may be applicable for the design of space-based systems.

Use of the jet-induced mixing process to control the thermodynamic state of propellents in storage tanks has been extensively investigated. Several mixing time correlations ${ }^{2-6}$ have been proposed based on the concentration equilibrium, thermal equilibrium, or pressure equilibrium. Most correlations were obtained for small scale cylindrical tanks with negligible buoyancy effects. In large systems, the buoyancy due to thermal stratification generally impedes the motion of the colder and denser jet flow and possibly prevents the jet flow from reaching the liquid surface. The mixing time correlation recently developed by Lin et al ${ }^{6}$ for a liquid hydrogen tank included the effect of buoyancy due to the thermal stratification. The Richardson number $(\mathrm{Ri})$ was used to characterize the buoyancy effect. The study of Lin et al. ${ }^{6}$ showed that the mixing time required to destroy the thermal stratification increases significantly with the increase in $\mathrm{Ri}$ when $\mathrm{Ri}>0.5$. However, the buoyancy effect can be neglected if $\mathrm{Ri} \leq 0.5$. The Richardson number was defined based on the jet submergence depth $\left(\mathrm{H}_{\mathrm{j}}\right)$ and the temperature difference between the interface and the jet $\left(\mathrm{T}_{\mathrm{s}}-\mathrm{T}_{\mathrm{j}}\right)$ at the begining of mixing process.

Several experiments ${ }^{7-11}$ have been conducted to study the steady state vapor condensation rate at the liquid-vapor interface in a tank with jet-induced mixing. For high jet submergence, $H_{j} / D_{s}>3$, Sonin et al. ${ }^{10}$ developed a vapor condensation rate correlation for a steam-water system with negligible buoyancy effect. Brown et al. ${ }^{11}$ extended this work to include the effect of the low jet submergence, $0.5<\mathrm{H}_{\mathrm{j}} / \mathrm{D}_{\mathrm{s}}<3$. The condensation correlation developed in Refs. 10 and 11 was expressed in terms of liquid subcooling $\left(\mathrm{T}_{\mathrm{s}}-\mathrm{T}_{\mathrm{b}}\right)$. The correlation was modified by Lin et al.$^{6}$ and was expressed as a function of jet subcooling $\left(\mathrm{T}_{\mathrm{s}}-\mathrm{T}_{\mathrm{j}}\right)$. The modified steady state condensation rate correlation was then used to predict the transient condensation rate in the fluid mixing of a hydrogen tank using the instantaneous value of jet subcooling. The limited liquid hydrogen data of Ref. 6 is fairly described by this modified condensation rate correlation.

The experimental work reported in Ref. 6 was performed with a small $\left(0.14 \mathrm{~m}^{3}\right)$ cylindrical tank with relatively low wall heat fluxes ( 3 to $30 \mathrm{~W} / \mathrm{m}^{2}$ ). Therefore, the effect of free convection boundary layer (along the tank wall) on the jetinduced mixing process was negligible. However, for a typical cryogenic storage system, the tank size may be large enough such that the flow rate of the warm fluid in the free convection boundary layer may be significant. This warm flow moves along the tank wall towards the interface and turns inward to oppose the subcooled jet. Consequently, evaporation may occur at the outer part of the interface (due to free convection flow) with condensation occurring at the inner part of the interface (due to jet flow). Therefore, the average vapor condensation rate at the interface will be reduced and the mixing time will be increased. The idealized flow pattern and phenomena are shown in Fig. 1.

This paper presents the experimental results in a large storage tank where the liquid hydrogen is mixed by an axial turbulent jet directed normally towards the liquid-vapor 
interface. The effect of jet volume flow rate and liquid fill level on the mixing time and the average vapor condensation rate at the interface is investigated. The influence of free convection flow due to wall heat leak on the mixing process and the resulting tank pressure change is also examined. The results are compared with those obtained for a small scale tank. $^{6}$

\section{The Experiment}

The tests were conducted at the NASA Lewis Research Center's K-Site Facility located at Plum Brook Station in Sandusky, Ohio. The test facility had a $7.6 \mathrm{~m}$ diameter spherical vacuum chamber enclosing a $4.0 \mathrm{~m}$ diameter cylindrical shroud which in turn enclosed the $\mathrm{LH}_{2}$ test tank. The test tank was suspended by fiberglass composite struts. The shroud was maintained at a constant temperature of $350 \mathrm{~K}$ by electrical resistance heating to obtain a constant heat input to the test tank. The pressure in the vacuum chamber during the test series was on the order of $10^{-4}$ to $10^{-3} \mathrm{~Pa}$.

The $\mathrm{LH}_{2}$ test tank was insulated with 2 blankets of multilayer insulation, each blanket consisted of 17 layers of double aluminumized Mylar separated by silk netting. The tank was constructed of 2219 aluminum and was approximately an ellipsoidal volume of revolution. The major-to-minor axis ratio was 1.2 with the major diameter of $2.2 \mathrm{~m}$. The test tank had a volume of $4.89 \mathrm{~m}^{3}$, an internal surface area of $14 \mathrm{~m}^{2}$, and a mass of $149 \mathrm{~kg}$. Most of the wall was $2.08 \mathrm{~mm}$ thick except for the thick bolted flange and lid at the top, thickened lands for support lugs, and a thickened equatorial region.

The experimental setup was basically the same as had been used for the self-pressurization tests in Refs. 1 and 12 . However, two systems were added in the present study: a pressurization system and a mixing system. The pressurization system was designed such that the pressurant $\left(\mathrm{GH}_{2}\right)$ was supplied from high pressure storage bottles at ambient temperature. A diffuser was installed near the top of the test article and the gas pressurant was fed into the vapor region directly. The pressurant flow rate was calculated from pressure drop measurements across a square edged orifice placed in the pressurant line. The orifice was instrumented with high and low range differential pressure transducers as well as an upstream pressure transducer and temperature sensor. A mixer unit was installed inside the test tank to generate axial jetinduced mixing. The mixer unit was the one designed for the Shuttle Centaur hydrogen tank and was the same one used in Ref. 6 . Figure 1 shows a schematic that depicts the mixer as installed in the elliptical test tank. The jet nozzle outlet had an inner diameter of $0.0221 \mathrm{~m}$ and was located in the center about $0.51 \mathrm{~m}$ from the tank bottom.

A capacitance probe was installed to measure the liquid fill level with an accuracy of $\pm 0.019 \mathrm{~m}$. Instrumentation rakes were used for the mounting of silicon diodes temperature sensors for temperature measurement. Locations of various temperature sensors in the test tank are shown in Fig. 2. The fluid temperatures and external tank wall temperature measurements had an accuracy of \pm 0.1 and $\pm 0.6 \mathrm{~K}$, respectively. Tank pressure was measured by pressure transducers in direct communication with the tank ullage with an accuracy of $\pm 0.7 \mathrm{~Pa}$. The pressurant flow rate measurement had an estimated accuracy of \pm 0.18 and $\pm 0.40 \mathrm{~kg} / \mathrm{hr}$ for the low and high range differential pressure transducers, respectively. The mixer flow rate was measured by a turbine flowmeter with an estimated accuracy of $\pm 0.02 \mathrm{~m}^{3} / \mathrm{hr}$.

The heat leak through the tank wall was determined from a boil-off test. The procedure was the same as that of Refs. 1 and 12 . With the shroud temperature maintained at $350 \mathrm{~K}$ the boil-off rate was about 5.6 SCMH (standard cubic meter per hour) which yielded an average wall heat flux of $4.2 \mathrm{~W} / \mathrm{m}^{2}$. In each test, the tank liquid was initially saturated at about $117 \mathrm{kPa}$. The tank was then pressurized either by using the pressurization system to introduce $\mathrm{GH}_{2}$ into the tank or by self-pressurization due to the ambient heat leak through the tank wall. If the tank was self-pressurized, the bulk liquid would be subcooled and thermally stratified. If the tank was pressurized by the introduction of $\mathrm{GH}_{2}$, thermal stratification would be limited to a very thin thermal layer undemeath the liquid surface. The mixer was turned on when the tank pressure reached a specified level. The test was terminated when the tank pressure reached a steady value or if the planned testing time was reached.

\section{Results and Discussion}

Three series of experiments consisting of ten tests were conducted. The tests were conducted at about 85 and 50 percent liquid fill levels (in volume) with the jet flow rate ranging from 0.91 to $5.63 \mathrm{~m}^{3} / \mathrm{hr}$. The initial condition of each mixing test was established by raising the tank pressure by selfpressurization or by the addition of gaseous hydrogen such that the bulk liquid was subcooled. Table I shows the experimental conditions for all the tests.

Within each test series, the initial conditions such as liquid fill and liquid subcooling were very similar and the only controlling variable was the jet volume flow rate. Therefore, within each test series, the effect of free convection flow (along the tank wall) on the mixing of tank fluid induced by various jet flow rates can be investigated. Figures $3(a)$ to (c) show the tank pressure decay as a function of time for various jet volume flow rates for all the test series. The pressure decay rate is faster for a higher jet flow rate as a result of the enhanced vapor condensation at the liquid-vapor interface. However, in test run 438, which has the lowest jet flow rate, the tank pressure increases with time during the mixing. This indicates that the net mass transfer at the liquid-vapor interface is evaporation due to the free convection flow along the tank wall. Also, the jet momentum may not be sufficient to overcome the opposing effect of buoyancy due to the thermal stratification. 
A solution for a turbulent free convection boundary layer with constant wall heat flux and uniform bulk temperature has been obtained by Vliet et al. ${ }^{13}$ using the velocity and temperature profiles employed by Eckert and Jackson ${ }^{14}$ in their analyses of turbulent free convection on a vertical plate at constant wall temperature. Using Vliet et al.'s results, the volume flow rate in the boundary layer for a cylindrical tank can be written as

$$
\mathrm{Q}_{b 1}(x)=0.292 \pi \mathrm{D} v^{1 / 7}\left(g \beta q_{w} / \rho C_{p}\right)^{2 / 7} x^{8 / 7}
$$

where $\mathrm{D}$ is the tank diameter and $\mathrm{x}$ is the distance measured from the tank bottom. It is obvious that $Q_{b l}$ increases significantly with the tank size. Equation (1) is used to estimate $\mathrm{Q}_{\mathrm{bl}}$ for the nearly ellipsoidal tank of the present study. With the modified Grashof number defined as $\mathrm{Gr}^{*}={\mathrm{g} \beta \mathrm{q}_{\mathrm{w}}} \mathrm{H}_{\mathrm{l}}^{4} / \mathrm{kv}^{2}$, the volume flow rate in the boundary layer at the interface location is estimated to be

$$
\mathrm{Q}_{\mathrm{bl}} *=0.292 \pi \mathrm{D}_{\mathrm{s}} v(\mathrm{Gr} * / \mathrm{Pr})^{2 / 7}
$$

where $D_{s}$ is the diameter of the liquid-vapor interface. Equation (2) is expected to over-predict the the volume flow rate in the natural convection boundary layer for an ellipsoidal tank. This is because of the effects of the tank wall curvature and the heat leak through the tank bottom. Due to buoyancy, the heating of the tank bottom generally creates a mixing region near the tank bottom and delays the formation (shifted upwards) of the thermal boundary layer at the sidewall due to sidewall heating. ${ }^{15}$

The analysis for a turbulent free circular jet is used to estimate the jet volume flow rate at the liquid-vapor interface location. According to Schlichting ${ }^{16}$, the volume flow rate $\left(Q_{c}\right)$, which increases with distance from the orifice due to the entrainment of the flow from the surroundings, can be calculated by

$$
Q_{c}(x)=0.456 Q_{j} \frac{x}{d}
$$

where $Q_{j}$ is the jet volume flow rate at the jet nozzle outlet, $x$ is the distance from the nozzle outlet, and $\mathrm{d}$ is the diameter of nozzle. The total jet volume flow rate at the liquid-vapor interface location is estimated to be

$$
Q_{c}^{*}=0.456 Q_{j} \frac{H_{j}}{d}
$$

The values of $\mathrm{Q}_{\mathrm{bl}}{ }^{*}$ and $\mathrm{Q}_{\mathrm{c}}{ }^{*}$ are listed in Table II. Fluid properties at $110 \mathrm{kPa}$ saturated condition were used to calculate $\mathrm{Qbl}_{\mathrm{bl}}$.

The jet induced flow $Q_{c}$ * brings colder fluid to the central part and the boundary flow $\mathrm{Q}_{\mathrm{bl}}{ }^{*}$ brings warmer fluid to the outer part of the surface. The net mass transfer at the interface results from condensation in the central part and evaporation in the outer part of the interface due to the flow rates $Q_{c}{ }^{*}$ and $\mathrm{Q}_{\mathrm{bl}}{ }^{*}$, respectively. Also, buoyancy due to thermal stratification may impede the upward motion of the colder and denser jet flow and may significantly reduce the condensation rate at the liquid-vapor interface. The findings of Refs. 6, 10, and 11 suggest that buoyancy effects may be quantified in terms of the Richardson number, Ri. Based on the definition of Ri used in Ref. 6, the buoyancy effects due to thermal stratification of the bulk liquid are insignificant if $\mathrm{Ri}<0.5$. Comparison of $\mathrm{Q}_{\mathrm{bl}}{ }^{*}$ and $\mathrm{Q}_{\mathrm{c}}{ }^{*}$ in Table $I$ and the pressure change rate during the mixing as shown in Figs. 3(a) to (c) shows that the effect of free convection flow along the tank wall on the jet mixing process decreases as the jet volume flow rate $\left(Q_{j}\right)$ and thus $Q_{c}{ }^{*}$ increases. In the test run 438 , the jet flow rate $Q_{j}$ is low such that $\mathrm{Q}_{c}{ }^{*}$ and $\mathrm{Q}_{b}{ }^{*}$ are comparable. The pressure increases with time during the mixing as shown in Fig. 3(a) which suggests that the net mass transfer at the liquid-vapor interface is evaporation. The condensation rate in the test run 438 may also have been significantly reduced due to relatively high value of Richardson number ( $R i=0.52$, in Table III). In the test run 459 , the tank pressure during mixing decreases even though $Q_{b]}{ }^{*}$ is greater than $Q_{c}{ }^{*}$. This is, in part, due to the fact that the Richardson number for this test is low $(R i=0.2$, in Table III). If the jet flow rate is high enough such that $Q_{c}{ }^{*}$ is much greater than $\mathrm{Q}_{\mathrm{bl}}{ }^{*}$, then there may be condensation occuring over most of the interface. As shown in Table II, the test run 471 represents this case.

As shown in Table I, test run 385 has the same jet volume flow rate as test run 438 . However, unlike test run 438, the tank pressure in test run 385 decreases (Fig. 3(c)) during the mixing process. This is because, for tank pressurization using gaseous hydrogen, the pressurization time required to reach the target tank pressure is too short for the free convection flow to be fully developed and also the liquid temperature is less stratified. Therefore, the effect of wall heat leak in the mixing process is greater in test series $A$ than in test series $C$.

The ratio of the liquid-vapor interface diameter to the jet nozzle diameter, $D_{s} / d$, ranged from 85 to 100 in all the tests. Thus, as the jet moved upward and reached the liquid surface, it had to travel a long distance in the radial direction before moving back towards the tank bottom. This made it difficult for the axial jet to induce complete mixing of the tank fluid. Therefore, unlike the experiments of Ref. 6 in which $D_{s} / d$ was about 25 , the thermal equilibrium state was not reached in these tests. Each test was terminated when the tank pressure reached a steady value or if the planned testing time was reached. Table III shows the mixing characteristics for all the tests. There are only five test runs (out of ten) in which the tank pressure reached a steady value when the test was terminated. In Ref. 6, the mixing time was defined as the time required for the tank to reach the equilibrium pressure. Thus, the mixing time measured for these five test runs can be used to compare 
the predictions of mixing time correlation developed in Ref. 6 for a small scale cylindrical tank:

$$
t_{m}^{*}=\frac{t_{m} u_{j} d}{D_{s}^{2}}=\left\{\begin{array}{cc}
3.3 & R i \leq 0.5 \\
2.6+2.1 R i & R i>0.5
\end{array}\right.
$$

From Table III, it is seen that the mixing time for test runs in which the tank pressure reached a steady value is underpredicted by Eq. (5). This may be due to the combined effects of natural convection flow, tank size, and tank geometry. The effect of natural convection flow can be investigated from the present data. Since in each test series, the modified Grashof number $\left(\mathrm{Gr}^{*}\right)$ is nearly constant, the effect of natural convection flow on the central jet flow will decrease as the jet Reynolds numbers (jet volume flow rates) increases. Therefore, as shown in Table III, the comparison improves as the jet Reynolds number $\left(\operatorname{Re}_{j}\right)$ and then the ratio $Q_{c}{ }^{*} / Q_{b l}{ }^{*}$ increase. Also, the comparison seems to be slightly better for test series $\mathrm{C}$ because the natural convection flow is not fully developed in these tests.

Vapor condensation at the interface is the key mechanism to reduce the tank pressure. Sonin et al. ${ }^{10}$ obtained an empirical correlation for the rate at which a pure saturated vapor condenses on the free surface of a turbulent liquid in a steamwater system, under conditions where buoyancy effects are insignificant. The vapor was saturated and the vapor condensation was controlled by the interface turbulence at the liquid side. Their vapor condensation rate correlation is expressed as

$$
\mathrm{St}_{\mathrm{c}}=0.0198 \operatorname{Pr}^{-0.33}(1-0.5 \mathrm{Ja})
$$

where $S t_{c}$, defined as $\left.S t_{c}=m_{c} h_{f g}\right]\left[A_{s} \rho C_{p} v_{s}\left(T_{s}-T_{b}\right)\right]$, is the average condensation Stanton number, $J a$ is the Jakob number, and $m_{c}$ is the average vapor mass condensation rate at the interface. Equation (6) is strictly valid for $\mathrm{Ja} \ll<1$. The liquid subcooling $\left(T_{s}-T_{b}\right)$ and average turbulence intensity at the interface $\left(v_{s}\right)$ are the controlling parameters for the vapor condensation rate.

The average turbulent r.m.s. velocity at the interface, $v_{\mathrm{s}}$, for low jet submergence can be determined by

$$
\begin{array}{r}
v_{s}=\frac{u_{j} d}{D_{s}}\left[10.04 \beta_{2}-\left(7.14 \beta_{2}-3.06 \beta_{1}\right) \frac{H_{j}}{D_{s}}\right] \\
\text { for } 0.5<H_{j} / D_{s}<3
\end{array}
$$

where $\beta_{1}=0.34$ and $\beta_{2}=0.24$ from Ref. 17 and $\beta_{1}=0.33$ and $\beta_{2}=0.23$ from Ref. 18 . For $\mathrm{Ja}<1$, the steady state correlation of Eq. (6) has been modified by Lin et al. ${ }^{6}$ for the application of transient cases:

$$
S t_{c}=\frac{m_{c} h_{f g}}{A_{s} \rho C_{p} v_{s}\left(T_{s}-T_{j}\right)}
$$

$$
\begin{aligned}
\times\left[1+\left(D_{s} / d\right)^{2}\right. & \left.\left(0.0198 \operatorname{Pr}^{-0.33}\right)\left(v_{s} / u_{j}\right)\right] \\
& =0.0198 \mathrm{Pr}^{-0.33}(1-0.5 \mathrm{Ja})
\end{aligned}
$$

where the liquid subcooling $\left(T_{s}-T_{b}\right)$ has been replaced by jet subcooling $\left(\mathrm{T}_{\mathrm{s}}-\mathrm{T}_{\mathrm{j}}\right)$ which is usually measured during the test. The jet subcooling as a function of time is shown in Figs. 4(a) to (c). According to the range of jet subcooling shown in Figs. 4(a) to (c), the Jakob number is less than 0.05 for all the tests.

Equation (8) is used to predict the change of vapor mass for the tests in test series $A$. The reason to use test series $A$ for comparison is that $H_{j} / D_{s}$ is about 0.5 and the vapor superheat for these tests is relatively mild. The vapor is superheated with the temperature difference $\left(T_{\text {dome }}-T_{s}\right)$ ranging from 40 to $100 \mathrm{~K}$ for test series $\mathrm{A}$. These conditions are relatively close to the applicable range of the correlation. The vapor mass is obtained from a curve-fitted one-dimensional temperature distribution. This one-dimensional calculation is a good approximation because the data indicates that the radial variation of the vapor temperature is small.

Figures 5(a) to (c) show the estimated vapor mass as a function of time. The vapor mass predicted by using Eq. (8) is also included in the figures for comparison. According to the previous discussion, Eq. (8) should over-predict the average condensation rate at the liquid-vapor interface because of the effect of natural convection flow. Figure 5(a) indeed shows this fact. As the jet volume flow rate increases, the comparison gets better. Surprisingly, Figs. 5(b) and (c) show that Eq. (8) under-predicts the average condensation rate. This can be explained by the fact that, in Figs. 5(b) (for test run 434) and (c) (for test run 471), the jet volume flow rate is sufficiently high that surface breakup occurs. The agitation of the liquidvapor interface induces significant condensation and Eq. (8), which was developed based on the assumption of a flat interface, does not apply. In Ref. 7, an equation was provided to estimate the condition for the onset of surface breakup:

$$
\operatorname{Re}_{\mathrm{j}} \geq 0.46(\Delta \rho \mathrm{g} \sigma)^{1 / 4} \mathrm{H}_{\mathrm{j}} /\left(\rho^{1 / 2} v\right)
$$

where $\Delta \rho$ is the density difference between the liquid and the vapor and $\sigma$ is the surface tension of the liquid. Equation (9) gives the prediction of minimum jet Reynolds number $\left(\operatorname{Re}_{\mathrm{j}}\right)$ for the jet to penetrate the liquid-vapor interface. Using this criteria, the jet Reynolds number for the onset of the surface breakup for the tests at 85 percent fill level is about 230000 . Comparing with the jet Renolds numbers listed in Table III, 
the jet Reynolds numbers for both test runs 434 and 471 are greater than 230000 . This comparison supports our argument associated with Figs. 5(b) and (c).

\section{Conclusion}

Experiments have been conducted to investigate the effect of fluid mixing on the depressurization of a large scale liquid hydrogen storage tank. Under the experimental conditions in the present study, the following conclusions can be drawn:

1. For a large cryogenic fluid storage tank subjected to very low wall heat flux of $4.2 \mathrm{~W} / \mathrm{m}^{2}$, the effect of natural convection flow on the jet induced mixing process may not be neglected. The boundary layer flow of warm fluid (along the tank wall) due to natural convection decreases the average condensation rate at the liquid-vapor interface and increases the mixing time.

2. The dimensionless mixing time for the tests under comparable conditions (Table III) is under-predicted by the correlation (Eq. (5)) developed based on small scale tank results.

3. The thermal equilibrium state is very difficult to achieve for fluid in a large scale mixing tank, i.e., in a tank with large ratio of liquid surface diameter to jet nozzle diameter.

\section{References}

1. Hasan, M.M, Lin, C.S., and Van Dresar, N.T., "SelfPressurization of a Flightweight Liquid Hydrogen Storage Tank Subjected to Low Heat Flux," Cryogenic Heat Transfer-1991, A. Adorjan and A. Bejan, eds., ASME HTD-Vol. 167.

2. Fossett, H. and Prosser, L.E., "The Application of Free Jets to the Mixing of Fluids in Bulk," Proceedings of the Institute of Mechanical Engineers, Vol. 160, No. 2, pp. 224-232, 1949.

3. Okita, N. and Oyama, Y., "Mixing Characteristics in Jet Mixing," Chem. Eng. Japan, IVol. 27, No. 4, pp. 252-259, 1963.

4. Wollen, M.A., Evaluation of Jet Induced Mixing for Centaur LH 2 Tank,".NASA TM-696083-333, August, 1983.

5. Poth, L.J. and Van Hook, J.R., "Control of Thermodynamic State of Space-Stored Cryogens by Jet Mixing," J. Spacecraft, Vol. 9, No. 5, pp. 332-336, 1972.
6. Lin, C.S., Hasan, M.M, and Nyland, T.W., "Mixing and Transient Interface Condensation of a Liquid Hydrogen Tank," AIAA Paper 93-1968, 1993.

7. Thomas, R.M., "Condensation of Steam on Water in Turbulent Motion," Int. J. Multiphase Flow, Vol. 5, No. 1, pp. 1-15, 1979.

8. Dominick, S.M., "Mixing Induced Condensation Inside Propellant Tanks," AIAA Paper 84-0514, 1984.

9. Meserole, J.S., Jones, O.S., Brennan, S.M., and Fortini, A., Mixing-Induced Ullage Condensation and Fluid Destratification," AIAA Paper 87-2018, 1987.

10. Sonin, A.A., Shimko, M.A., and Chun, J.H., "Vapor Condensation onto a Turbulent Liquid-I. The Steady State Condensation Rate as a Function of Liquid-Side Turbulence," Int. J. Heat Mass Trans., Vol. 29, No. 9, pp. 1319-1332, 1986.

11. Brown, J.S., Helmick, M.R., and Sonin, A.A., "Vapor Condensation at a Turbulent Liquid Surface in Systems with Possible Space-Based Application," AIAA Paper 89-2846, 1989.

12. Van Dresar, N.T., Lin, C.S., and Hasan, M.M., "SelfPressurization of a Flightweight Liquid Hydrogen Tank: Effects of Fill Level at Low Heat Flux," AIAA Paper 92-0818,1992.

13. Vliet, G.C., Brogan, J.J., Sheppard, T.S., Morse, F.H., and Hines, F.L., "Stratified Layer Flow Model: A Numerical Approach to Liquid Temperature Stratification," J. Spacecraft, Vol. 1, No. 6, pp. 666-672, 1964.

14. Eckert, E.R.G. and Jackson, J.W., "Analysos of Turbulent Free-Convection Boundary Layer on Flat Flate,"NACA Rept. 1015, pp. 255-261, 1951

15. Tatom, J.W., Brown, W.H., Knight, L.H., and Coxe, E.F., "Analysis of Thermal Stratification of Liquid Hydrogen in Rocket Propellant Tanks," Advances in Cryogenic Engineering, Vol. 9, pp. 265-272, 1963.

16. Schlichting, H., "Boundary Layer Theory", McGraw Hill, pp. 749, 1979.

17. Brown, J.S., Khoo, B.C., and Sonin, A.A., "Rate Correlation for Condensation of Pure Vapor on Turbulent, Subcooled Liquid," Int. J. Heat Mass Trans., Vol. 33, No. 9, 1990.

18. Lin, C.S. and Hasan, M.M., "Effect of Liquid Surface Turbulent Motion on the Vapor Condensation in a Mixing Tank," Proceedings of the 4th International Symposium on Transport Phenomena in Heat and Mass Transfer, Sudney, Australia, 14-19 July, 1991, Transport Phenomena in Heat and Mass Transfer, edited by J.A. Reizes, pp. 1526-1537, 1992 
TABLE I.-EXPERIMENTAL CONDITIONS FOR MIXING TESTS

\begin{tabular}{|c|c|c|c|c|c|c|c|c|}
\hline \multirow{2}{*}{$\begin{array}{l}\text { Test } \\
\text { run } \\
\text { no. }\end{array}$} & \multirow{2}{*}{$\begin{array}{c}\text { Pressurization } \\
\text { source }\end{array}$} & \multicolumn{2}{|c|}{ Initial Liquid Fill } & \multirow{2}{*}{$\begin{array}{c}Q_{i} \\
\left(\mathrm{~m}^{3} / \mathrm{hr}\right)\end{array}$} & \multirow{2}{*}{$\begin{array}{l}D_{s} \\
(m)\end{array}$} & \multirow{2}{*}{$\underset{(\mathrm{kPa})}{\mathrm{P}_{\mathrm{i}}}$} & \multirow{2}{*}{$\underset{(\mathrm{kPa})}{\mathrm{P}_{\mathrm{f}}}$} & \multirow{2}{*}{$\begin{array}{l}\left(\mathrm{T}_{\mathrm{s}}-\mathrm{T}_{\mathrm{j}}\right)_{\mathrm{i}} \\
(\mathrm{K})\end{array}$} \\
\hline & & $\%$ & $V_{1}\left(m^{3}\right)$ & & & & & \\
\hline \multicolumn{9}{|c|}{ Test Series A } \\
\hline 438 & $S$ & 86.9 & 4.25 & 0.91 & 1.87 & 187.0 & 193.5 & 1.7 \\
\hline 436 & S & 85.3 & 4.17 & 1.82 & 1.91 & 187.0 & 131.6 & 1.7 \\
\hline 434 & $S$ & 86.3 & 4.22 & 3.47 & 1.88 & 186.1 & 128.4 & 1.7 \\
\hline 471 & $S$ & 81.6 & 3.99 & 5.63 & 1.99 & 186.3 & 117.8 & 1.9 \\
\hline \multicolumn{9}{|c|}{ Test Series B } \\
\hline 459 & $s$ & 48.3 & 2.36 & 0.91 & 2.22 & 186.3 & 158.3 & 1.6 \\
\hline 457 & $S$ & 49.1 & 2.40 & 1.82 & 2.22 & 186.5 & 149.5 & 1.6 \\
\hline 449 & $\mathrm{~S}$ & 49.1 & 2.40 & 3.41 & 2.22 & 186.1 & 145.8 & 1.6 \\
\hline \multicolumn{9}{|c|}{ Test Series C } \\
\hline 385 & G & 85.3 & 4.17 & 0.93 & 1.91 & 178.5 & 158.7 & 1.7 \\
\hline 387 & G & 84.3 & 4.12 & 1.82 & 1.93 & 181.2 & 127.8 & 1.7 \\
\hline 389 & G & 84.9 & 4.15 & 3.40 & 1.92 & 182.2 & 121.8 & 1.7 \\
\hline
\end{tabular}

S: Self-pressurization

G: Gaseous hydrogen pressurant

TABLE 2.-COMPARISON OF VOLUME FLOW RATE AT THE INTERFACE LOCATION DUE TO THE CENTRAL JET AND THE NATURAL CONVECTION FLOW

\begin{tabular}{|c|c|c|c|c|c|c|}
\hline $\begin{array}{c}\text { Test } \\
\text { Run No. }\end{array}$ & $\begin{array}{c}\text { Jet submergence } \\
\text { depth, } H_{j}(m)\end{array}$ & $\begin{array}{c}\mathrm{Q}_{\mathrm{c}}{ }^{*} \\
\left(\mathrm{~m}^{3} / \mathrm{hr}\right)\end{array}$ & $\begin{array}{c}\text { Liquid Height } \\
\mathrm{H}_{1}(\mathrm{~m})\end{array}$ & $\begin{array}{c}\text { Interface } \\
\text { Dia., } D_{s}(m)\end{array}$ & $\mathrm{Gr}^{*}$ & $\underset{\left(\mathrm{m}^{3} / \mathrm{hr}\right)}{\mathrm{Q}_{\mathrm{b}}}$ \\
\hline \multicolumn{7}{|c|}{ Test Series $\mathbf{A}^{\mathbf{a}}$} \\
\hline $\begin{array}{l}438 \\
436 \\
434 \\
471\end{array}$ & $\begin{array}{l}0.95 \\
0.92 \\
0.94 \\
0.86\end{array}$ & $\begin{array}{l}17.8 \\
34.5 \\
67.3 \\
99.9\end{array}$ & $\begin{array}{l}1.46 \\
1.43 \\
1.45 \\
1.37\end{array}$ & $\begin{array}{l}1.87 \\
1.91 \\
1.88 \\
1.99\end{array}$ & $\begin{array}{l}9.2 \times 10^{14} \\
8.4 \times 10^{14} \\
8.9 \times 10^{14} \\
7.1 \times 10^{14}\end{array}$ & $\begin{array}{l}20.0 \\
20.0 \\
20.0 \\
19.8\end{array}$ \\
\hline \multicolumn{7}{|c|}{ Test Series $B^{2}$} \\
\hline $\begin{array}{l}459 \\
457 \\
449\end{array}$ & $\begin{array}{l}0.41 \\
0.42 \\
0.42\end{array}$ & $\begin{array}{r}7.7 \\
15.8 \\
29.6\end{array}$ & $\begin{array}{l}0.92 \\
0.93 \\
0.93\end{array}$ & $\begin{array}{l}2.22 \\
2.22 \\
2.22\end{array}$ & $\begin{array}{l}1.4 \times 10^{14} \\
1.5 \times 10^{14} \\
1.5 \times 10^{14}\end{array}$ & $\begin{array}{l}14.0 \\
14.2 \\
14.2\end{array}$ \\
\hline \multicolumn{7}{|c|}{ Test Series $C^{b}$} \\
\hline $\begin{array}{l}385 \\
387 \\
389\end{array}$ & $\begin{array}{l}0.92 \\
0.90 \\
0.91\end{array}$ & $\begin{array}{l}17.7 \\
33.8 \\
63.8\end{array}$ & $\begin{array}{l}1.43 \\
1.41 \\
1.42\end{array}$ & $\begin{array}{l}1.91 \\
1.93 \\
1.92\end{array}$ & $\begin{array}{l}----^{\mathfrak{c}} \\
---- \\
---\end{array}$ & $\begin{array}{l}---\mathfrak{c} \\
--- \\
---\end{array}$ \\
\hline
\end{tabular}

aSelf-pressurization.

${ }^{\mathrm{b}}$ Gaseous hydrogen pressurant.

cThe natural convection flow is not fully developed. 
TABLE 3.-THE MIXING CHARACTERISTICS OF THE TESTS

\begin{tabular}{|c|c|c|c|c|c|c|c|}
\hline $\begin{array}{c}\text { Test } \\
\text { Run No. }\end{array}$ & $\mathrm{Re}_{\mathrm{j}}$ & $\mathrm{Ri}$ & $\mathrm{H}_{\mathrm{j}} / \mathrm{D}_{\mathrm{s}}$ & $\begin{array}{c}\mathrm{u}_{\mathrm{j}} \\
(\mathrm{m} / \mathrm{s})\end{array}$ & $\mathrm{t}_{\mathrm{m}}{ }^{* \mathrm{a}}$ & $\mathrm{t}_{\mathrm{m}}{ }^{* \mathrm{~b}}$ & $\mathrm{Q}_{\mathrm{c}}{ }^{*} / \mathrm{Q}_{\mathrm{bl}}{ }^{*}$ \\
\hline \multicolumn{7}{|c|}{ Test Series A } \\
\hline 438 & 80000 & 0.52 & 0.51 & 0.66 & --- & -- & 0.89 \\
436 & 160000 & 0.13 & 0.48 & 1.32 & $13.1^{\mathrm{c}}$ & 3.3 & 1.73 \\
434 & 304000 & 0.036 & 0.50 & 2.51 & $7.49^{\mathrm{c}}$ & 3.3 & 3.37 \\
471 & 495000 & 0.014 & 0.43 & 4.08 & $9.11^{\mathrm{c}}$ & 3.3 & 5.05 \\
\hline \multicolumn{7}{|c|}{ Test Series B } \\
\hline 459 & 80000 & 0.20 & 0.18 & 0.66 & 15.1 & 3.3 & 0.55 \\
457 & 161000 & 0.049 & 0.19 & 1.33 & 12.7 & 3.3 & 1.11 \\
449 & 299000 & 0.014 & 0.19 & 2.47 & $16.8^{\mathrm{c}}$ & 3.3 & 2.08 \\
\hline \multicolumn{7}{|c|}{ Test Series C } \\
\hline 385 & 82000 & 0.49 & 0.48 & 0.68 & 2.3 & 3.3 & --- \\
387 & 161000 & 0.13 & 0.47 & 1.33 & 4.4 & 3.3 & --- \\
389 & 296000 & 0.038 & 0.47 & 2.44 & $8.2^{\mathrm{c}}$ & 3.3 & --- \\
\hline
\end{tabular}

aDimensionless time based on the measurement.

DDimensionless uime based on the prediction of Eq. (5).

${ }^{c}$ Test was terminated when the tank pressure reached a steady value.

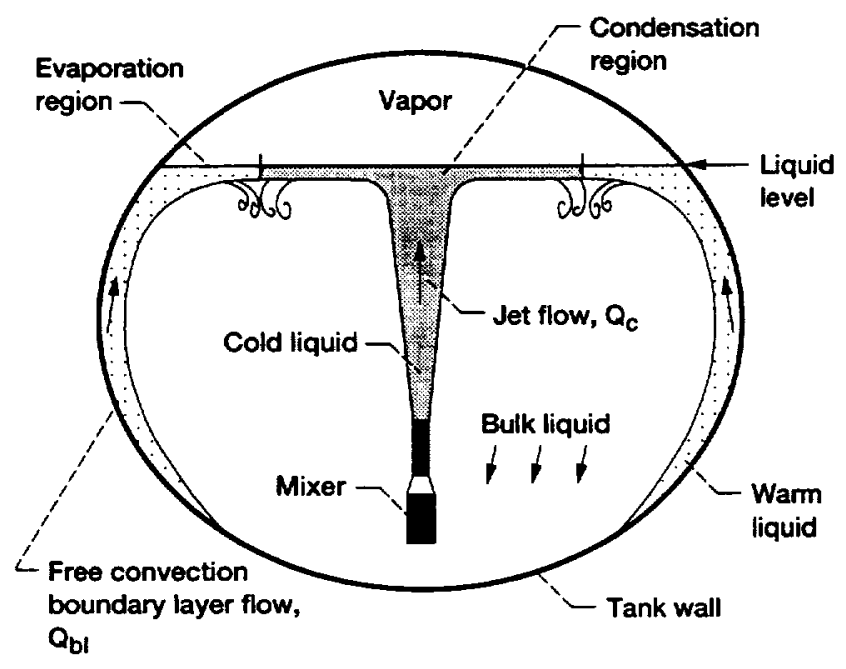

Figure 1.-The flow pattem and phenomena of a mixing tank.

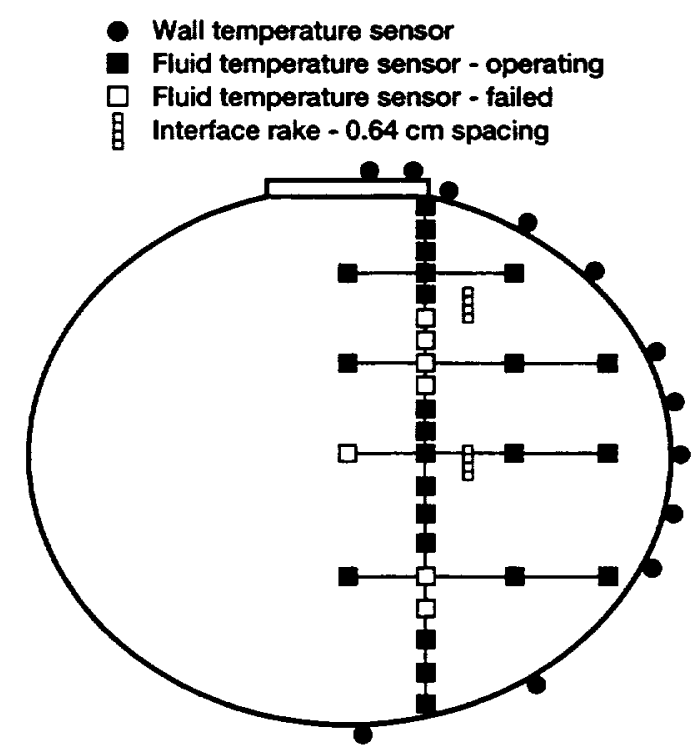

Figure 2,-Tank instrumentation. 

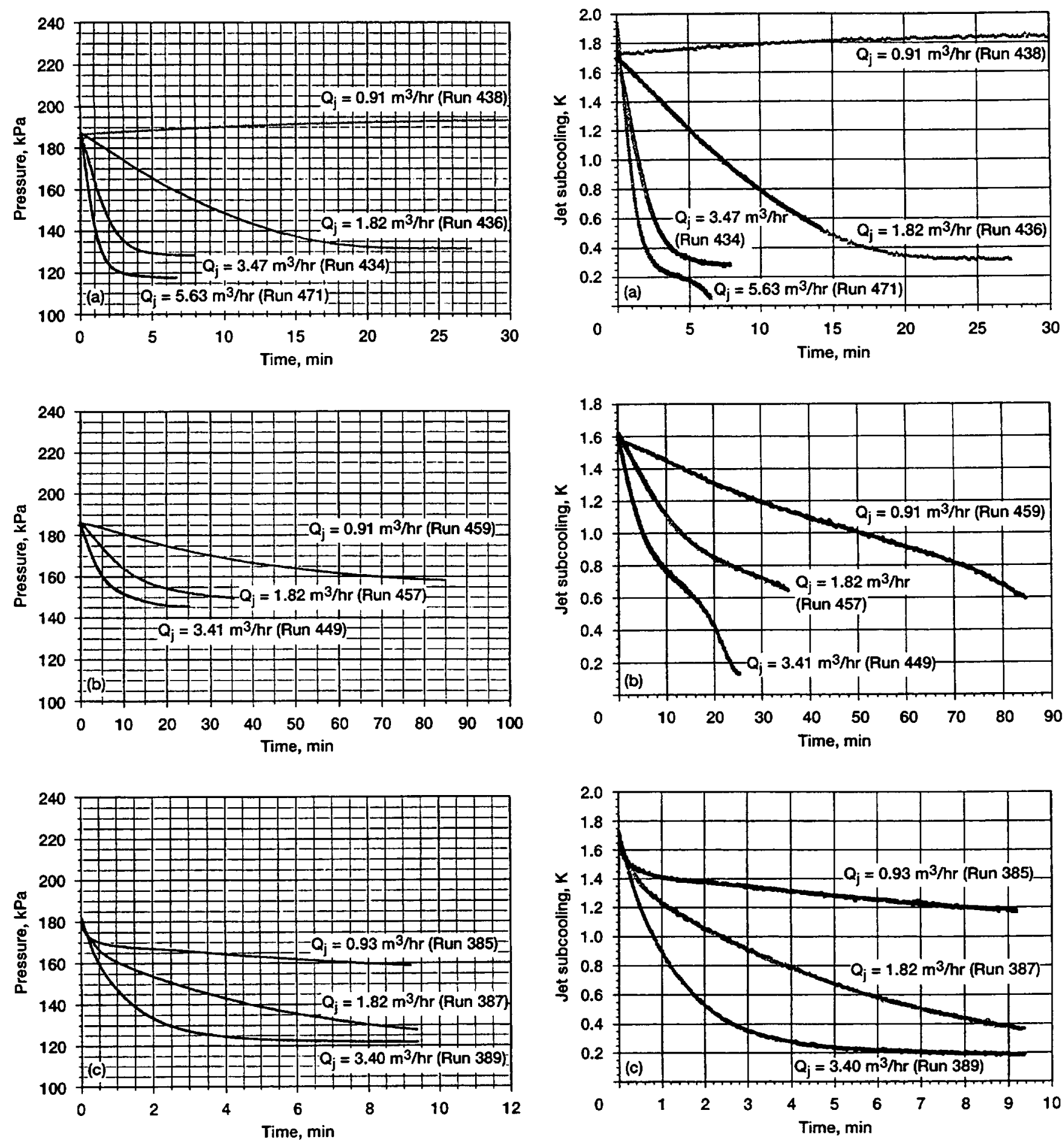

Figure 3.-Pressure decay as a function of time. (a) For test series A. (b) For test series B. (c) For test series C.

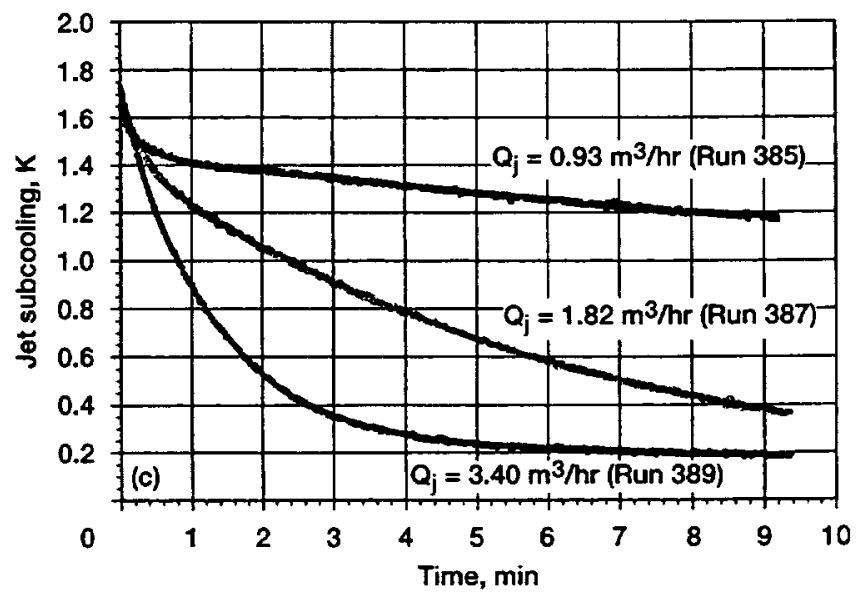

Figure 4. Jet subcooling as a function of time. (a) For test series A. (b) For test series B. (c) For test series C. 

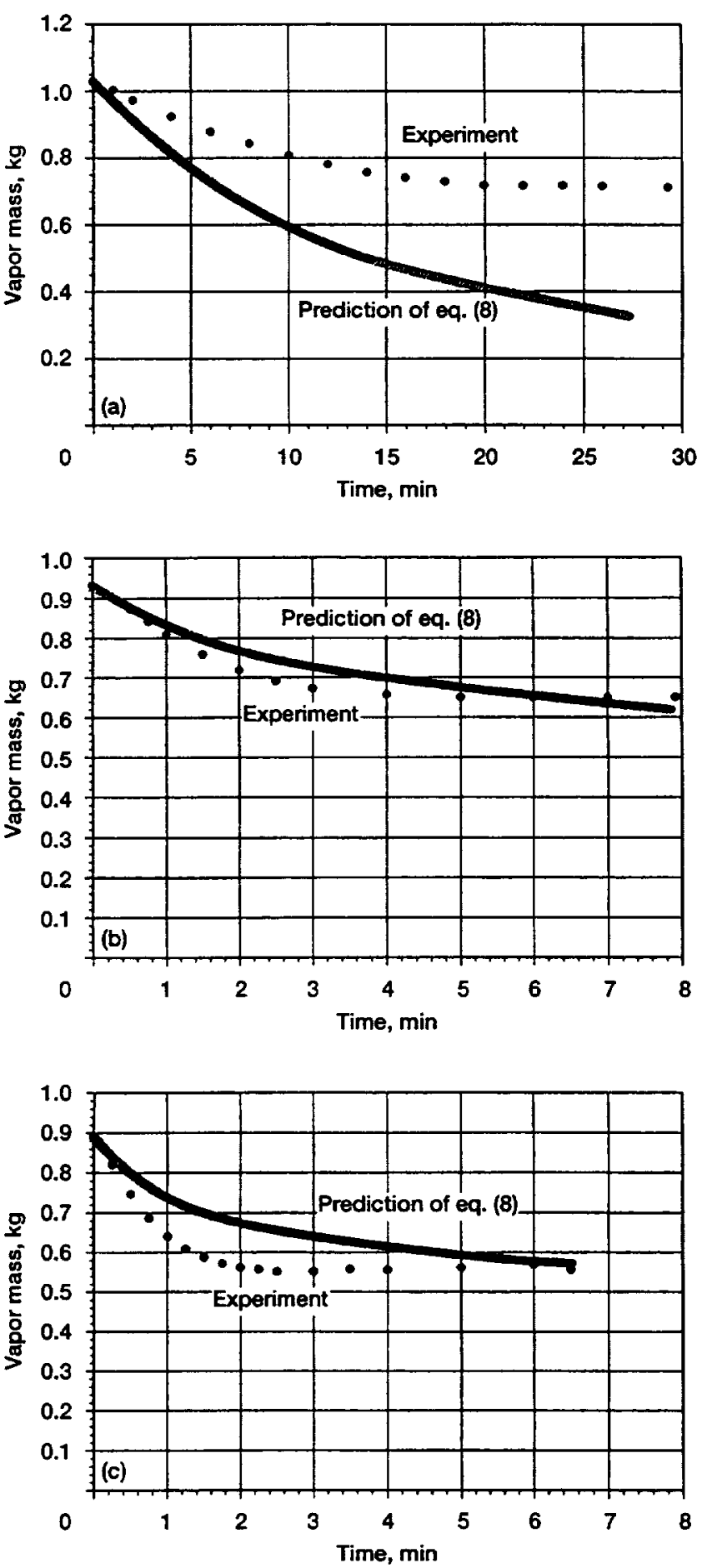

Figure 5.-The change of vapor mass as a function of time. (a) For test run 436; $Q_{j}=1.82 \mathrm{~m}^{3} / \mathrm{hr}$. (b) For test run $434 ; Q_{j}=3.47 \mathrm{~m}^{3} / \mathrm{hr}$. (c) For test run $471 ; Q_{j}=5.63 \mathrm{~m}^{3} / \mathrm{hr}$. 
Public reporting burden for this collection of information is estimated to average 1 hour per response, inctuding the time for reviewing instructions, searching existing data sources. gathering and maintaining the data needed, and completing and reviewing the collection of information. Send comments regarding this burden estimate or any other aspect of this collaction of information, including suggestions for reducing this burden, to Washington Headquarters Services, Directorate for Information Operations and Reports, 1215 Jefferson Davis Highway, Suite 1204, Arlington, VA 22202-4302, and to the Office of Management and Budget, Paperwork Reduction Project (0704-0188), Washington, DC 20503.

\begin{tabular}{|l|c|c|}
\hline 1. AGENCY USE ONLY (Leave blank) & $\begin{array}{c}\text { 2. REPORT DATE } \\
\text { June } 1994\end{array}$ & $\begin{array}{r}\text { 3. REPORT TYPE AND DATES COVERED } \\
\text { Technical Memorandum }\end{array}$ \\
\hline
\end{tabular}

4. TITLE AND SUBTITLE

5. FUNDING NUMBEAS

Experimental Investigation of Jet-Induced Mixing of a Large Liquid Hydrogen Storage Tank

6. AUTHOR(S)

WU-506-42-73

C. S. Lin, M. M. Hasan, and N. T. Van Dresar

7. PERFORMING ORGANIZATION NAME(S) AND ADDRESS(ES)

8. PERFORMING ORGANIZATION REPORT NUMBER

National Aeronautics and Space Administration

Lewis Research Center

Cleveland, Ohio 44135-3191

E-8926

9. SPONSORINGMONITORING AGENCY NAME(S) AND ADDRESS(ES)

10. SPONSORINGMONITORING AGENCY REPORT NUMBER

National Aeronautics and Space Administration

Washington, D.C. 20546-0001

NASA TM-106629

AIAA-94-2079

\section{SUPPLEMENTARY NOTES}

Prepared for the 6th Joint Thermophysics and Heat Transfer Conference cosponsored by the American Institute of Aeronautics and Astronautics and the American Society of Mechanical Engineers, Colorado Springs, Colorado, June 20-23, 1994. Chin-Shun Lin, Analex Corporation, 3001 Aerospace Parkway, Brook Park, Ohio 44142 (work funded by NAS3-25776); Mohammad M. Hasan and Neil T. Van Dresar, NASA Lewis Research Center. Responsible person, Mohammad M. Hasan, organization code 5340, (216) 433-7494.

12a. DISTRIBUTIONAVAILABILITY STATEMENT

12b. DISTRIBUTION CODE

Unclassified - Unlimited

Subject Category 34

\section{ABSTRACT (Maximum 200 words)}

Experiments have been conducted to investigate the effect of fluid mixing on the depressurization of a large liquid hydrogen storage tank. The test tank is approximately ellipsoidal, having a volume of $4.89 \mathrm{~m}^{3}$ and an average wall heat flux of $4.2 \mathrm{~W} / \mathrm{m}^{2}$ due to external heat input. A mixer unit was installed near the bottom of the tank to generate an upward directed axial jet flow normal to the liquid-vapor interface. Mixing tests were initiated after achieving thermally stratified conditions in the tank either by the introduction of hydrogen gas into the tank or by self-pressurization due to ambient heat leak through the tank wall. The subcooled liquid jet directed towards the liquid-vapor interface by the mixer induced vapor condensation and caused a reduction in tank pressure. Tests were conducted at two jet submergence depths for jet Reynolds numbers from 80000 to 495000 and Richardson numbers from 0.014 to 0.52 . Results show that the rate of tank pressure change is controlled by the competing effects of subcooled jet flow and the free convection boundary layer flow due to external tank wall heating. It is shown that existing correlations for mixing time and vapor condensation rate based on small scale tanks may not be applicable to large scale liquid hydrogen systems.

14. SUBJECT TERMS

Liquid hydrogen storage tank; Jet mixing; Pressure decay; Vapor condensation 15. NUMBER OF PAGES 12

SECURITY CLASSIFICATION OF REPORT Unclassified
18. SECUATTY CLASSIFICATION OF THIS PAGE Unclassified
19. SECURITY CLASSIFICATION OF ABSTRACT Unclassified 